\title{
Review of temporal bone dissection teaching: how it was, is and will be
}

\author{
A P GEORGE, R DE*
}

\begin{abstract}
Objective: We aimed to review the history of anatomical dissection, and to examine how modern educational techniques will change the way temporal bone dissection is taught to otolaryngology trainees. Method: Review of the literature using Medline, Embase and PubMed database searches.

Results: Temporal bone anatomy has traditionally been taught using cadaveric specimens. However, resources such as three-dimensional reconstructed models and 'virtual reality' temporal bone simulators have a place in educating the otolaryngology trainee.

Conclusion: We should encourage the use of fresh frozen cadaveric temporal bone specimens for future otologists. Artificial three-dimensional models and virtual reality temporal bone simulators can be used to educate junior trainees, thus conserving the scarce resource of cadaveric bones.
\end{abstract}

Key words: Temporal Bone; Anatomy; Dissection; Computer Simulation

\section{Introduction - how it was}

For years, otologists have agreed that, in the words of Duckworth et al:

An essential way of learning temporal bone anatomy and surgical technique is through repeated dissections of the temporal bone in a cadaver dissection. ${ }^{1}$

Understanding the contents and intimate relationships of the temporal bone is essential for all ENT trainees. ${ }^{2-7}$

\section{Anatomy teaching}

Recorded interest in human anatomy dates from 1600 BC Egyptian papyrus documents, which stated, 'vessels to the right ear carried the breath of life as opposed to vessels to the left ear that carried the breath of death'.

In the fourth century BC, Hippocrates and Aristotle advanced knowledge further, expounding a fundamental understanding of the musculoskeletal system. Around that period, Hereophilos and Erasistratus were involved in the first ever documented dissection of cadavers. In the second century, Galen produced an anatomical textbook, his Canon of Medicine, which stood the test of time for 1500 years. In the Middle Ages, with the advent of the printing press, Galen's work was circulated, criticised and modified. This inspired the true anatomical 'renaissance', in which ideas were exchanged through the illustrated press and anatomists' popularity equated to their drawing talent. An era of anatomical teaching had begun, and with it a demand for fresh bodies that could only be obtained following execution.

During the nineteenth century, the systematic approach to anatomy was adopted. There was a significant demand for cadaveric dissection, prompting the gruesome actions of the murderers William Burke and William Hare. The Anatomy Act of 1832 was implemented to legitimise and regulate the practice of cadaveric dissection. This shifted anatomical dissections from the public theatre into the realms of medical schools and teaching hospitals, and heralded the concept of anatomy teaching courses. The first travelling doctor's anatomy guide, inspired by Henry Gray, was published in 1858 .

Historically, religious powers had restricted the provision of cadavers for dissection. In the modern day, there has been a gradual change towards parliamentary law steered by public opinion. In the UK, the Human Tissue Act of 1961 meant that human tissue could be legally obtained for education and research from three sources: university departments of morbid anatomy, hospital post-mortem examinations and coroner post-mortem examinations. Further legislation - the 1984 Anatomy Act and the 1988 Anatomy Regulations - concentrated on the importance of consent from the individual for use of their body for medical research. ${ }^{8,9}$ However, it was not clear how the bodies were to be used, distributed and disposed of, and whether in fact any

From the Department of SpR ENT, University Hospital of North Staffordshire, Stoke on Trent, and the *Department of ENT, Birmingham Queen Elizabeth Hospital, Birmingham, UK.

Accepted for publication: 26 June 2009. First published online 3 December 2009. 
body parts would be retained, thus leading to the Alder Hey and Bristol tissue retention scandals. Parliament reacted, and in April 2006, the Human Tissues Act of 2004 was implemented under the administration of the Human Tissue Authority. ${ }^{10}$ The practice of obtaining and using any human tissue for medical education or research would now depend on informed consent.

\section{Surgical training}

'See one, do one, teach one', medical trainees are advised. The apprenticeship model of surgical education has withstood the test of time until recently. ${ }^{11}$ The residency-based style of surgical training, pioneered by Sir William Halsted in the late nineteenth century, guaranteed exposure to a wide range of surgical pathology. ${ }^{12}$ The limiting factor for trainee's learning was their own stamina and determination. Traditional methods of surgical education focused on the need for experience in order to gain insight and to refine surgical skills - 'the more you do, the more you know'.

Due to the challenges of temporal bone surgery, it is necessary for trainees to develop improved hand-eye coordination, to learn a command of fine motor skills and to obtain thorough anatomical knowledge under magnified vision. Therefore, residents spent an inordinate amount of time working to develop these skills. The combination of surgical experience and laboratory cadaveric dissection has resulted in otologists of excellent quality.

All medical schools used cadaveric dissection as part of their anatomy training. Experience in cadaveric dissection at postgraduate level is obtained through attending various dissection courses worldwide. Under the 1984 and 1988 UK anatomy acts, medical schools were a crucial source of specimens, particularly in the case of temporal bone dissection as this anatomical region was untouched in undergraduate dissection. However, the 1984 and 1988 acts clearly stated that the dissection of cadavers was to be confined exclusively to the demonstration and exploration of human anatomy, and expressly forbade the use of cadavers for the practice or demonstration of surgical technique. The practice of cadaveric dissection in order to gain anatomical knowledge and experience in temporal bone handling was strongly encouraged by the British Association of Otolaryngology and Head and Neck Surgeons; however, this asset to surgical education is becoming increasingly difficult to sustain.

This review aims to explore the challenges encountered in training otologists in the art of temporal bone dissection, in light of recent difficulties in obtaining cadaveric temporal bones. It will explore alternatives to cadaveric dissection for UK trainees, discussing the merits of each, and will also review advances in medical educational theory.

\section{How it is}

The law

Under the Human Tissue Act of 2004, removal of human tissue after death is governed by identical rules, whether for medical research, education or transplantation (see Table I). ${ }^{10}$

Worldwide, there seems to be ample availability of temporal bones for dissection via a range of temporal bone courses, which have recently been appraised by trainees in a report in ENT News. ${ }^{13}$

\section{Cadaveric dissection}

The USA has its own National Temporal Bone Hearing and Balance Pathology Resource Registry (within the National Institute on Deafness and Other Communication Disorders (NIDCD)), based at the Massachusetts Eye and Ear Infirmary (http:// www.tbregistry.org), in order to satisfy the demand for cadaveric temporal bones. This organisation encourages individuals with ear disorders to pledge their temporal bones at death to scientific research. Leong and Aldren explored the possibility of a similar UK registry, and found that 70 per cent of their cohort of ENT patients supported the concept of temporal bone donation for medical education and research. ${ }^{5}$

Once a temporal bone is harvested, formaldehyde or a high concentration of alcohol is used to preserve the tissue. This results in the loss of natural colour, something that can be important for skeletonising the facial nerve during dissection. Frozen temporal bones offer better colour, consistency and contrast, but carry a real risk of viral transmission (e.g. hepatitis B)..$^{14}$

Feigl et al. reported positive findings in their study of cadaveric dissection and otologists' learning curves. ${ }^{4}$ For single surgeons performing single operative techniques, they demonstrated a significant improvement in surgeons' anatomical understanding and ability to perform a specified procedure, over sequential attempts at singular nerve neurectomy on a cadaver. What this study actually demonstrates is that practice improves outcome and repetitive cadaveric dissection is needed for a successful outcome. Does this mean practice by any means available will produce the same effect?

\section{Alternatives to cadaveric dissection}

There are a number of alternatives to cadaveric dissection via which practising otologists can acquaint themselves with the theoretical and practical aspects of the temporal bone.

\section{TABLE I}

SECTION 3, HUMAN TISSUE ACT 2004 $4^{10}$

1 The deceased himself gave appropriate consent before he dies; or if he gave no consent, but nor did he veto organ donation;

2 Consent is given by the deceased's nominated representative - that is a person expressly nominated by the deceased to make decisions about the use of his body parts before his death; or if the deceased neither made his own decision about donation nor nominated a representative;

3 Consent is given by a close family member or friend what is described as 'a person who stood in a qualifying relationship with the deceased before his death'. 
Regarding theory and conceptual understanding, anatomy texts vary in their depth of description of temporal bone osteology and of the landmarks used for surgical navigation. ${ }^{15}$ A number of authors have published three-dimensional models and interactive atlases, and have supplied detailed descriptions recreated from reconstruction of either high resolution computed tomography (CT) or histological sections. ${ }^{16-27}$ Kavanagh has published a sequence of histological slides from the human temporal bone, available at http://www.ear-anatomy.com. ${ }^{28}$ Sun et al. have used three-dimensional reconstruction to build a physical model of the entire middle ear. ${ }^{29}$

Three-dimensional computer models have been validated as useful educational tools with which to increase clinical understanding of the topographical relationships of various structures within the temporal bone. ${ }^{16}$ Entering 'temporal bone' into a 'YouTube' search will deliver a number of online dissection videos.

At present, the alternatives to cadaveric temporal bone dissection are plastic models, porcine dissection and virtual reality temporal bone simulators. ${ }^{30}$ All have been well documented in the literature; however, cadaveric dissection always appears to set the standard against which other methods must compare in order to gain general acceptance as valid training alternatives to live surgery.

Virtual reality simulators are demonstrating validity as training and skills assessment tools. ${ }^{3}$ They allow any task to be replicated in order to facilitate education and assessment, giving the learner the opportunity to try new skills, make mistakes and allow competency to evolve. ${ }^{31}$ Thus, new skills are developed without risk to a patient, and there is no time constraint.

The same could be said for the temporal bone models mentioned above. However, learning is restricted by the models' availability to each trainee. Such models allow trainees to practice otology procedures such as myringotomy and grommet insertion, tympanotomy, ossiculoplasty, and stapes surgery. Laser sintering techniques are used to create an accurate, three-dimensional representation of temporal bone anatomy. Mori and colleagues' temporal bone model incorporates surface details, inner bony structure and air cells; a future version will include dura mater, cranial nerves, venous sinuses and the internal carotid artery. ${ }^{2}$ These authors claim that dissection of the model can be performed in the same way as in a real cadaver. The Pettigrew bone, utilised in the Glasgow temporal bone training course, comprises a plastic model with coloured dyes to highlight the facial nerve, sigmoid sinus and carotid artery. The addition of red irrigation fluid simulates bleeding during drilling. The middle-ear trainer designed by Mills and Lee consists of a number of ear modules representing different surgical problems. ${ }^{32}$ In contrast to the Pettigrew bone, a pinna is attached to the model to enable practice incisions.

The major advantage of a plastic model is that it obviates the need for the laboratory conditions required for cadaveric dissection. Scott et al. investigated the risk of prion transmission during laboratory temporal bone drilling. ${ }^{6}$ They demonstrated microscopic evidence of neural tissue in the cloud of bone dust created during such drilling. Many surgeons now wear eye protection during surgery, but this precaution must also be used in cadaveric temporal bone laboratories (amongst other precautions to reduce infection risk). However, this limits availability and increases the costs of cadaveric dissection. The Spongiform Encephalopathy Advisory Committee of the UK Advisory Committee on Dangerous Pathogens has made recommendations for work involving potentially prion-infected material, including the use of a microbiology isolation chamber; these recommendations are shown in Table II, and compared with the precautions taken in most Cadaveric Temporal Bone Dissection (CTBD) laboratories. ${ }^{33}$

In 1988, Harada et al. used histological sections to reconstruct the temporal bone in three dimensions, in order to understand the stereoscopic relationships of the contained structures. ${ }^{34}$ They generated images based upon the entire volume of each section (a technique known as volume rendering). Trainee interaction with a three-dimensional temporal bone based upon a haptic interface (the VR-Tool) was first proposed in 1997 by Kuppersmith et al. ${ }^{35}$ Further developments by Stredney et al. provided a stereoscopic display with haptic feedback and aural simulation. ${ }^{36} \mathrm{~A}$ multimodal interface simulated the drilling and cutting of bone.

Wiet and colleagues investigated the creation of a virtual environment to rival a cadaver laboratory. ${ }^{37,38}$ Visual images were created by virtual binoculars to simulate a microscope, and two PHANToM ${ }^{\circledR}$ force feedback tools replicated the drill and suction. Three-dimensional images were obtained from CT reconstructions of cadaveric temporal bones. A haptic algorithm used volume rendering data and adjusted a set of virtual springs around the virtual burr, enabling different haptic feedback for each type of burr used. Bone erosion was implemented by decreasing the density of the voxels (threedimensional pixels) in contact with the virtual burr. ${ }^{39}$ An aural interface incorporated a change in pitch of the virtual burr, depending on virtual bone thickness. Their model gained acceptance amongst practising otologists as a training tool.

TABLE II

ADVISORY COMMITTEE ON DANGEROUS PATHOGENS RECOMMENDATIONS FOR WORK WITH POTENTIALLY PRION-INFECTED MATERIAL

\begin{tabular}{lcc}
\hline Safety equipment & $\begin{array}{c}\text { ACDP } \\
\text { Recommendations }\end{array}$ & $\begin{array}{c}\text { Temp bone } \\
\text { lab }\end{array}$ \\
\hline Disposable gowns & + & + \\
Disposable gloves & + & + \\
Disposable instruments & + & - \\
Full-face visors* & + & - \\
$\begin{array}{l}\text { Microbiology safety } \\
\text { cabinet or isolation } \\
\text { chamber }\end{array}$ & + & - \\
\hline
\end{tabular}

*Usually masks and goggles. Temp = temporal 
Pflesser et al. also developed a volumetric, high resolution model of the temporal bone, using a new technique of realistic visualisation of simulated cut surfaces, the Voxel-Man TempoSurg simulator for middle-ear surgery (Spiggle and Thies, Overath, Germany; http://www.uke.de/voxel-man). ${ }^{40}$ In this system, the operator uses a foot pedal to control the virtual drill and wears specialised glasses to view a computer-generated image in three dimensions. As well as tactile haptic feedback, the angle of view and magnification can be adjusted, as in the operating theatre.

Subsequent development of simulators has focused on real-time feedback directly associated with a specific action. For example Agus and colleagues' 'Integrated Environment for Rehearsal and Planning of Surgical Interventions' simulator predominantly aimed to replicate the visual and haptic effects of a real operation. ${ }^{39}$ This project was a three-year, European Union funded scheme incorporating technological advancements in: spatial co-recognition, tissue segmentation with voxel partial volume averaging, physical modelling, visual feedback, image rendering, haptic feedback, and spatiotemporal realism. The technological innovations used to create this simulator have been reviewed by Jackson et al. ${ }^{41}$

\section{Discussion - how it will be \\ Educational theory}

Before disregarding alternatives to cadaveric dissection, we must look at current training requirements and expectations. Previous training programmes relied upon sheer volume of exposure, but this is now not the case. Surgical skills are increasingly being taught in the laboratory. To make time spent in training more efficient, a greater understanding of educational theory has been sought. New training techniques can be modelled on the widely accepted, three-stage theory of motor skill acquisition expounded by Fitts and Posners (Table III). ${ }^{42}$

The early stages of learning should take place outside the operating theatre, until the trainee has autonomous skills and can focus on more technical issues whilst still ensuring patient safety. Halm and colleagues' systematic review demonstrated a positive relationship between operative volume and

TABLE III

FITTS AND POSNER'S THEORY OF MOTOR SKILL ACQUISITION

Stage 1 (cognitive stage)

A process of intellectualising the task. Performance is erratic and the procedure is being carried out in distinct steps.

Stage 2 (integrative stage)

Knowledge of the task is transferred to motor behaviours. The student still thinks about how to move their hands but is able to execute the task more fluidly.

Stage 3 (autonomous stage)

The performance is smoother and there is no need to think about movements, allowing the student to concentrate on learning other aspects of the procedure.

Published with permission. ${ }^{42}$ positive clinical outcome. ${ }^{43}$ However, Ericsson argues that it is the number of hours spent in deliberate practice, rather than the hours spent in surgery, which determines the level of expertise reached. ${ }^{44}$ Deliberate practice, as described by Reznick and MacRae, involves repetition and immediate feedback on performance. ${ }^{42}$ Therefore, one may argue that, in the early stages of learning temporal bone surgery, the use of three-dimensional plastic models and virtual reality temporal bone simulators could play a pivotal role. As regards the availability of plastic models, supply could meet demand simply by streamlining production. The supply of such plastic models as the Glasgow Pettigrew bone and Mill's middle-ear surgery trainer is currently limited as each is hand-crafted, but there is scope for mass production. ${ }^{32}$ There is no limit to the number of repeated dissections available on a virtual reality temporal bone simulator.

\section{Competency assessment}

A key factor in any training environment is not just the acquisition of new skills but also anatomical knowledge and performance feedback.

Wiet and colleagues' 'Ohio VRTB' virtual reality temporal bone simulator incorporated an 'Intelligent Tutor' programme with which the user could learn to identify anatomy easily by querying the system on the location of different structures.

Several validated rating scales for assessment skills already exist, such as the 'Objective Structured Assessments of Technical Skills' system. ${ }^{31}$ These scales are external measures that require third party input from a fully trained senior surgeon. Butler et al. proposed the Welling Scale as a standardised, objective, reliable and valid method of assessing technical skill in human temporal bone dissection. ${ }^{11,45}$ This scale was used to score both cadaveric and Pettigrew temporal bones drilled by candidates, and demonstrated good to excellent inter- and intra-rater reliability in assessing performance.

Zirkle et al. have studied assessment of dissection using a virtual reality temporal bone simulator. ${ }^{31}$ They acknowledged the validity of external assessment tools, whilst pointing out that the major drawback of external assessment is the scarcity of qualified assessors. The internal assessment tools built into Zirkle and colleagues' virtual reality temporal bone simulators were based on hand motion analysis in time and space as the task was performed. Assessment involved four particular parameters: distance covered, time spent on task, speed of motion and number of movements; a score was then generated which corresponded to external ratings used to compare experienced and trainee otologists. Zirkle and colleagues' internal assessment tool was validated by showing a significant increase in hand motion skill for the experienced surgeons when compare to trainee surgeons.

Other metric and performance feedback tools have been described for use in conjunction with virtual reality temporal bone simulators. ${ }^{46,47}$ One reported internal assessment tool allows the trainee 
to progress at their own rate without the need for constant supervision.

Virtual reality temporal bone simulators have huge potential as educational resources in the current educational climate. They can be incorporated into a systematic, structured training curriculum such as the Inter-Collegiate Surgical Curriculum Project, by means of the Direct Observation of Procedural Skills component. O'Leary et al. assessed the validity of a virtual reality temporal bone simulator environment. ${ }^{48}$ Participants were taught cortical mastoidectomy on the author's own networked virtual environment, then asked to perform the procedure on a cadaveric temporal bone. Networking allowed both the trainee and trainer to separately view the same virtual dissection whilst 'operating' in the same 'operating theatre'. The trainer could provide real-time haptic feedback, by demonstrating how to use the drill, and could also highlight areas of bone that required further drilling. This and another study by Hutchins et al. have emphasised important aspects of temporal bone surgery which can be learned using virtual reality temporal bone simulators, and have demonstrated a positive response to networked haptic learning environments amongst otology trainees. ${ }^{49}$

\section{The future of cadaveric temporal bone dissection}

We have previously discussed the reasons for the difficulty in obtaining cadaveric temporal bones for dissection and surgical training. Despite advances in three-dimensional models and virtual reality temporal bone simulators, nothing can quite substitute for the real thing. ${ }^{7}$ Human temporal bones provide an irreplaceable and invaluable resource for the study of the pathology and pathophysiology of disorders of hearing, balance, taste, facial nerve function and facial pain. ${ }^{50}$

Cadaveric temporal bone dissection also provides invaluable experience of anatomical variation. Peidong and colleagues' analysis of high resolution CT images from 66 normal temporal bones investigated the spatial relationship between the facial nerve and other structures within the temporal bone, and found that the position of the jugular bulb affected the position of the facial nerve. ${ }^{51}$ Such anatomical variation must be appreciated during the development of three-dimensional models and virtual reality temporal bone simulators, in order to create a realistic experience paralleling actual cadaveric dissection.

The Royal College of Surgeons of England recognises the importance of cadaveric dissection for all surgical trainees. ${ }^{52}$ The Hill Surgical Workshop (established in 1995) provides an environment in which trainees can perform dissections on 'soft-fix' cadavers. This preservation technique reduces tissue rigidity and hardness and allows easier dissection, compared with formalin fixation. Virtual simulation of surgery on soft tissues is computationally demanding, thus increasing costs. ${ }^{41}$ The 2004 Human Tissues Act has removed the objection to the use of cadavers for surgical techniques; thus, with appropriate guidance, soft-fix temporal bone laboratories which take into account health and safety issues (regarding infection) may represent the future. Until a US-style donor register is set up in the UK, the scarcity of temporal bones will remain a key issue in the use of cadaveric dissection for teaching ENT trainees.

Cadaveric bones are, and will continue to be, of key importance in research concerning new surgical techniques. Copeland et al. utilised cadaveric bones to validate the accuracy of computer-aided surgery in neurotological approaches to the temporal bone. ${ }^{53}$ Majdani et al. used human temporal bones to show the success of image-guided surgical technology in enabling drilling for a minimally invasive cochleostomy during cochlear implant surgery. ${ }^{54}$ Such conclusions would be difficult to validate on either a virtual reality temporal bone simulator or three-dimensional plastic model.

On the other hand, plastic models created by laser sintering techniques have been proven useful in surgical simulation, by Suzuki et al. ${ }^{55,56}$ These authors produced three-dimensional models of patients with congenital aural atresia, in order to facilitate presurgical planning. Plastic models may perhaps represent a cost-effective way for trainees to practice surgical techniques, for both normal and abnormal anatomy. Cheaper 'low fidelity' alternatives can be useful in the cognitive stages of learning a surgical skill; examples include Owa and colleagues' 'homemade' simulator for middle-ear stapes prosthesis placement, and Farrior's 'home' temporal bone laboratory. $57-59$

\section{Role for temporal bone simulation}

Simulation-based training is a prerequisite for organisations requiring high levels of reliability, such as the air, nuclear and oil industries. In the past, the real issue with the use of virtual reality temporal bone simulators for surgical training has been cost. However, due to advances in computing technology and power, this has significantly decreased. The effect of high and low fidelity simulation for surgical procedures carried out by junior trainees has been investigated by Matsumoto et al. ${ }^{60}$ They compared groups instructed in ureteric stone retrieval either didactically or with low or high fidelity simulation models. They demonstrated a significant effect for 'hands-on' training compared with didactic teaching, but no difference between high and low fidelity groups. Anastakis et al. found that bench training models were comparable to cadaveric dissection for transferring skills into the operating theatre at a junior level. ${ }^{61}$ In order to reduce the cost of virtual reality temporal bone simulators, low fidelity simulators could be used for competency-based assessment. As the trainee becomes more experienced, high fidelity simulation may be more beneficial.

\section{Conclusion}

'Expertise over experience' - this is the future, and the onus is on the ENT community to create an environment in which expertise can flourish, by 
using our resources in the best possible way. Increased understanding of the cognitive process of skill acquisition has indicated that, during the early stages of training, three-dimensional models and virtual reality temporal bone simulators are more than adequate to meet trainees' needs. We have also established ways in which such training could be assessed. The holistic benefits of cadaveric dissection would be better utilised once trainees have reached the 'autonomous' stage. We should establish a fresh frozen temporal bone register to benefit trainees likely to progress into the final years of training. It is these trainees who will compete for the few neurotology fellowships worldwide, of which there are only two in the UK. By redirecting a valuable, limited resource, we can improve the efficiency of ENT training.

\section{References}

1 Duckworth EAM, Silva FE, Chandler JP, Batjer HH, Zhao JC. Temporal bone dissection for neurosurgery residents: identifying the essential concepts and fundamental techniques for success. Surg Neurol 2008;69:93-8

2 Mori K, Yamamoto T, Oyama K, Ueno H, Nakao Y, Honma K. Modified three dimensional skull base model with artificial dura mater, cranial nerves and venous sinuses for training in skull base surgery: technical note. Neurol Med Chir (Tokyo) 2008:48:582-7, 587-8

3 Fried MP, Uribe JI, Sadough BB. The role of virtual reality in surgical training in otorhinolaryngology. Curr Opin Otolaryngol Head Neck Surg 2007;15:163-9

4 Feigl G, Kos I, Anderhuber F, Guyot JP, Fasel J. Development of surgical skill with singular neurectomy using human cadaveric temporal bones. Ann Anat 2008;190: 316-23

5 Leong AC, Aldren C. 'Bones of contention': a donor register for temporal bone donation? J Laryngol Otol 2007; 121:932-7

6 Scott A, De R, Sadek SAA, Garrido MC, CourteneyHarris RG. Temporal bone dissection: a possible route for prion transmission? J Laryngol Otol 2001;115:374-5

7 Browning GG. Training in temporal bone surgical skills. ENT News 2000;9:22-3

8 Morris DP, Benbow EW, Ramsden RT. 'Bones of Contention'. The donation of temporal bones for dissection after the organ-retention scandals. J Laryngol Otol 2001;115: $689-93$

9 Morris DP, Luff A, Hargreaves SP, Rothera MP. Bones of contention. The supply of temporal bones for dissection: the legalities, problems and solutions. J Laryngol Otol 1998;112:1138-41

10 The Human Tissue Act 2004. New Legislation On Human Organs And Tissue. London: Department of Health, 2004

11 Fernandez SA, Wiet GJ, Butler NN, Welling B, Jarjoura D. Reliability of surgical skills scores in otolaryngology residents: analysis using generalizability theory. Eval Health Prof 2008;31:419-36

12 Aggarwal R, Darzi A. Technical skills training in the 21st century. N Engl J Med 2006;355:2695-6

13 Pothier D. Choosing a temporal bone course. ENT News 2009;17:104-7

14 Golding-Wood DG. Temporal bone dissection for display. J Laryngol Otol 1994;108:3-8

15 Rhoton AL. Anatomy and surgical approaches of the temporal bone and adjacent areas. Neurosurg 2007;61(Suppl 4): S4-1

16 Jun BC, Song SW, Cho JE, Park CS, Lee DH, Chang KH et al. Three-dimensional reconstruction based on images from spiral high-resolution computed tomography of the temporal bone: anatomy and clinical application. J Laryngol Otol 2005;119:693-8

17 Sørensen MS, Dobrzeniecki AB, Larsen P, Frisch T, Sporring J, Darvann TA. The visible ear: a digital image library of the temporal bone. ORL $J$ Otorhinolaryngol Relat Spec 2002;64:378-81

18 Morra A, Tirelli G, Rimondini A, Cioffi V, Russolo M, Giacommara V et al. Usefulness of virtual endoscopic three-dimensional reconstructions of the middle ear. Acta Otolaryngol 2002;122:382-5

19 Karhuketo TS, Dastidar PS, Ryymin PS, Laasonen EM, Puhakka HJ. Virtual endoscopy imaging of the middle ear cavity and ossicles. Eur Arch Otorhinolaryngol 2002; 259:77-83

20 Chan LL, Manolidis S, Kaber KH, Hayman LA. Surgical anatomy of the temporal bone: an atlas. Neuroradiol 2001:43:797-808

21 Nayak S. Segmental anatomy of the temporal bone. Semin Ultrasound CT MR 2001;22:184-218

22 Mason TP, Applebaum EL, Rasmussen M, Millman A, Evenhouse R, Panko W. Virtual temporal bone: creation and application of a new computer-based teaching tool. Otolaryngol Head Neck Surg 2000;122:168-73

23 Mason TP, Applebaum EL, Rasmussen M, Millman A, Evenhouse R, Panko W. The virtual temporal bone. Stud Health Technol Inform 1998:50:346-52

24 Gunlock MG, Gentry LR. Anatomy of the temporal bone. Neuroimaging Clin N Am 1998;8:195-209

25 Reisser C, Schubert O, Forsting M, Sartor K. Anatomy of the temporal bone: detailed three-dimensional display based on image data from high-resolution helical CT: a preliminary report. Am J Otol 1996;17:473-9

26 Ahuja AT, Yuen HY, Wong KT, Yue V, Van Hasselt AC. Computed tomography imaging of the temporal bone normal anatomy. Clin Radiol 2003;58:681-6

27 Wang H, Northrop C, Burgess B, Liberman MC, Merchant $\mathrm{SN}$. Three-dimensional virtual model of the human temporal bone: a stand-alone, downloadable teaching tool. Otol Neurotol 2006;27:452-7

28 Kavanagh KT. World Wide Web-based temporal bone anatomic sections. Otolaryngol Head Neck Surg 2002;126: $573-7$

29 Sun Q, Chang KH, Dormer KJ, Dyer RK, Gan RZ. An advanced computer-aided geometric modeling and fabrication method for human middle ear. Med Eng Phys 2002:24:595-606

30 Barrs DM, Trahan CJ, Casey K, Brooks D. The porcine model for intratemporal facial nerve trauma studies. Otolaryngol Head Neck Surg 1991;105:845-56

31 Zirkle M, Roberson DW, Leuwer R, Dubrowski A. Using a virtual reality temporal bone simulator to assess otolaryngology trainees. Laryngoscope 2007;117:258-63

32 Mills R, Lee P. Surgical skills in training in middle-ear surgery. J Laryngol Otol 2003;117:159-63

33 ACDP (Advisory Committee on Dangerous Pathogens Spongiform Encephalopathy Advisory Committee). Transmissible Spongiform Encephalopathy Agents: Safe Working and the Prevention of Infection. London: HMSO, 1998

34 Harada T, Ishii S, Tayama N. Three-dimensional reconstruction of the temporal bone from histologic sections. Arch Otolaryngol Head Neck Surg 1988;114:1139-42

35 Kuppersmith RB, Johnston R, Moreau D, Loftin RB, Jenkins $\mathrm{H}$. Building a virtual reality temporal bone dissection simulator. Stud Health Technol Inform 1997;39:180-6

36 Stredney D, Wiet GJ, Bryan J, Sessanna D, Murakami J, Schmalbrock P et al. Temporal bone dissection simulation - an update. Stud Health Technol Inform 2002:85:507-13

37 Wiet GJ, Stredney D, Sessanna D, Bryan JA, Welling B, Schmalbrock P. Virtual temporal bone dissection: an interactive surgical simulator. Otolaryngol Head Neck Surg 2002; 127:79-83

38 Wiet GJ, Schmalbrock P, Powell K, Stredney D. Use of ultra-high-resolution data for temporal bone dissection simulation. Otolaryngol Head Neck Surg 2005;133:911-15

39 Agus M, Giachetti A, Gobetti E, Zanetti G, Zorcolo A. Tracking the movement of surgical tools in a virtual temporal bone dissection simulator. Med Image Computing and Computer assisted Intervention LNCS 2003;2673:100-7

40 Pflesser B, Petersik A, Tiede U, Höhne KH, Leuwer R. Volume cutting for virtual petrous bone surgery. Comput Aided Surg 2002;7:74-83 
41 Jackson A, John NW, Thacker NA, Ransden RT, Gillespie JE, Gobetti E et al. Developing a virtual reality environment in petrous bone surgery: a state of the art review. Otol Neurotol 2002;23:111-21

42 Reznick RK, MacRae H. Teaching surgical skills changes in the wind. $N$ Engl J Med 2006;355:2664-9

43 Halm EA, Lee C, Chassin MR. Is volume related to outcome in health care? A systematic review and methodologic critique of the literature. Ann Intern Med 2002;137: 511-20

44 Ericsson KA. The acquisition of expert performance: an introduction to some of the issues. In: Ericsson KA, ed. The Road to Excellence: the Acquisition of Expert Performance in the Arts and Sciences, Sports, and Games. Mahwah, New Jersey: Lawrence Erlbaum Associates, 1996:1-50

45 Butler NN, Wiet GJ. Reliability of the Welling scale (WS1) for rating temporal bone dissection performance. Laryngoscope 2007; 117:1803-8

46 Sewell C, Morris D, Blevins NH, Dutta S, Agrawal S, Barbagli $\mathrm{F}$ et al. Providing metrics and performance feedback in a surgical simulator. Comput Aided Surg 2008;13: 63-81

47 Morris D, Sewell C, Blevins N, Barbagli F, Salisbury K. A collaborative virtual environment for the simulation of temporal bone surgery. Medical Image Computing and Computer assisted Intervention 2004;3217:319-27

48 O'Leary SJ, Hutchins MA, Stevenson DR, Gunn C, Krumpholz A, Dipl-Ing et al. Validation of a networked virtual reality simulation of temporal bone surgery. Laryngoscope 2008;118:1040-6

49 Hutchins MA, Stevenson DR, Gunn C, Krumpholz A, Adriaansen T, Pyman B et al. Communication in a networked haptic virtual environment for temporal bone surgery training. Virt Real 2006;9:97-107

50 Nadol J. Techniques for human temporal bone removal: information for the scientific community. Otolaryngol Head Neck Surg 1996;115:298-305

51 Dai P, Zhang T, Wang K, Song J, Qian W, Wang Z. Positional relationship between the facial nerve and other structures of the temporal bone. J Laryngol Otol 2004; 118:106-11

52 Mahadevan V. Using unembalmed cadavers in surgical training. Bulletin of the Royal College of Surgeons of England 2009;3:80-1

53 Copeland BJ, Senior BA, Buchman CA, Pillsbury HC. The accuracy of computer-aided surgery in neurotologic approaches to the temporal bone: a cadaver study. Otolaryngol Head Neck Surg 2005;132:421-8

54 Majdani O, Bartling SH, Leinung M, Stöver T, Lenarz M, Dullin $\mathrm{C}$ et al. Image-guided minimal-invasive cochlear implantation: experiments on cadavers [in German]. Laryngorhinootologie 2008;87:18-22

55 Suzuki M, Hagiwara A, Kawaguchi S, Ono H. Application of a rapid-prototyped temporal bone model for surgical planning. Acta Otolaryngol 2005;125:29-32

56 Suzuki M, Ogawa Y, Hagiwara A, Yamaguchi H, Ono H. Rapidly prototyped temporal bone model for otological education. ORL J Otorhinolaryngol Relat Spec 2004;66: $62-4$

57 Owa AO, Gbejuade HO, Giddings C. A middle-ear simulator for practicing prosthesis placement for otosclerosis surgery using ward-based materials. J Laryngol Otol 2003;117:490-2

58 Farrior JB. Stapedectomy for the home temporal bone dissection laboratory. Otolaryngol Head Neck Surg 1986; 94:521-5

59 Farrior JB. Home temporal bone dissection: anatomic approaches to ear surgery. Otolaryngol Head Neck Surg 1980;88:310-15

60 Matsumoto ED, Hamstra SJ, Radomski SB, Cusimano MD. The effect of bench model fidelity on endourological skills: a randomized controlled study. J Urol 2002;167: 1243-7

61 Anastakis DJ, Regehr G, Reznick RK, Cusimano M, Murnaghan J, Brown $\mathrm{M}$ et al. Assessment of technical skills transfer from the bench training model to the human model. Am J Surg 1999;177:167-70

Address for correspondence:

Mr Ajith P George,

17 Moreton Place, Scholar Green,

Cheshire ST7 3LZ, UK.

E-mail: georgea288@aol.com

Mr A P George takes responsibility for the integrity of the content of the paper.

Competing interests: None declared 